
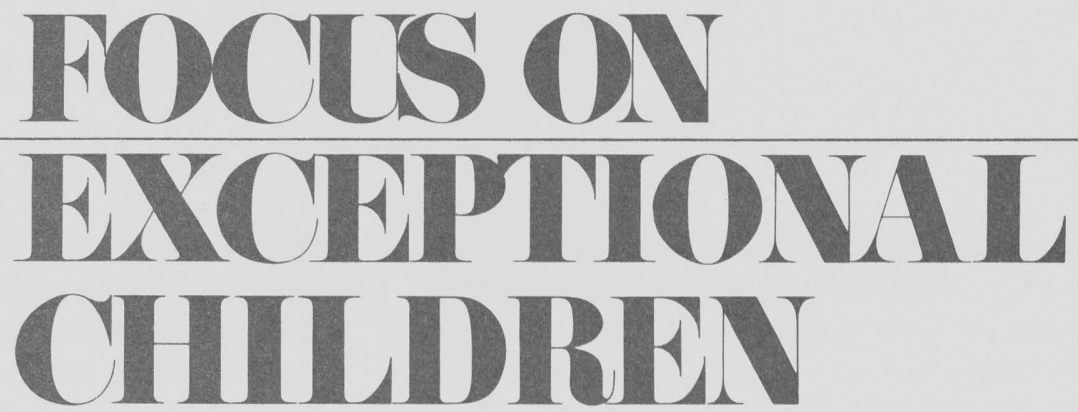

\title{
A Positive View of Standardized Tests
}

Dale P. Scannell

A few years ago a sage and perceptive connoisseur of popular topics observed that it had been established beyond any reasonable doubt that smoking was the single most important cause of - statistics. The parallel between implications of this statement and the currently popular flurry of anti-test articles is interesting to ponder. Cigarette packages now must carry the warning that smoking is dangerous to your health; and some critics of testing, it seems, will not be satisfied until a similar caveat appears on the covers of all test booklets: "It has been determined by (someone) that testing is dangerous to your personal health and happy existence."

Attacks and counterattacks concerning testing have appeared in a variety of sources - newspapers, weekly popular news magazines, journals of various organizations, and general professional journals (including those that represent the testing professionals). The attacks have been based on a variety of issues but, generally, the counterattacks have only stressed the errors in the attacks. The apologists of standardized tests usually have taken a defensive position, criticizing the critics for misinformation, lack of information, distortion of facts, or of impure motives. The apology for standardized testing represented by this article hopefully will avoid the counterattack mentality by focusing on the positive attributes and potential values of standardized tests within an egalitarian educational system and democratic social order, which the author presumes to be accurately descriptive of United States institutions, in theory if not in practice. 
Rather than criticizing the critics of standardized tests - an activity of questionable value - an attempt will be made first to analyze some major reasons for and factors related to the frequency of recent anti-test literature. Although specific features of standardized tests have prompted some of the attacks, it seems likely that tests have been partially victimized by manifestations of general concern about current educational practice. Second, all practices and procedures are based on some premises - as true for the use of standardized tests as for face creams. Thus, some premises concerning education and the role of schools as a social institution will be presented and discussed here - the purpose being to provide rationale for asserting that standardized tests can be useful tools for enhancing educational effectiveness. To the extent that the premises are unacceptable, the case for standardized tests likely will be also.

\section{FACTORS RELATED TO CRITICISMS OF STANDARDIZED TESTS}

That standardized testing is a popular target for some professional educators, journalists, and other members of the general public should not be surprising. Testing is a

FOCUS ON EXCEPTIONAL CHILDREN is published monthly except June, July, and August as a service to teachers, special educators, curriculum specialists, administrators, and those concerned with the special education of exceptional children. This journal is abstracted and indexed in Exceptional Child Education Abstracts, and is also available in microfilm from Xerox University Microfilms, Ann Arbor, Michigan. Subscription rates, $\$ 10.00$ per year. Copyright 1978, Love Publishing Company. All rights reserved. Reproduction in whole or part without written permission is prohibited. Printed in the United States of America. Second class postage is paid at Denver, Colorado.

Executive and Editorial Office 6635 East Villanova Place Denver, Colorado 80222 Telephone (303) 757-2579

\section{EDITORIAL BOARD}

Edward L. Meyen University of Kansas
Glenn A. Vergason Georgia State University

Richard J. Whelan

University of Kansas Medical Center

Carolyn Acheson

Senior Editor
Stanley F. Love Publisher highly visible activity, providing tangible results that will be pleasing to some, unpleasant for others. In some ways and in the minds of some people, testing is a symbol of what the schools are or for which they strive. Since the institution itself has some forcefully vocal critics, testing is bound to come in for its share of the harsh words.

\section{The Public Dichotomy on School Purposes}

Over the past 20 years schools often have been criticized for being too impersonal, a factory that processes information into the heads of children with no regard for the personal or human elements of growth and maturation. Concurrently, schools have been faulted for promoting a soft, standardless curriculum that allowed the Russians to be the first into space, that permits illiterates to receive high school diplomas, that emphasizes the socialization of youth to the neglect of academic achievement. To see the evidence of this paradox, one need only review the stated intentions of the private alternative schools that have been started in recent years. In almost equal numbers these form a dichotomy, with the proponents of "back to the basics" or "subjectcentered" schools in one camp and proponents of "humanistic," "social growth," "personalized" schools in the other.

The critics holding to these two extreme positions are withdrawing support of the schools for reasons that are virtually opposite. The schools they criticize and condemn are the same schools, but the perceptions are in direct contrast. It is little wonder that education is characterized by cycles of goals and procedures. Under the circumstances, bizarre, even random, behavior of school personnel could be expected as attempts are made to satisfy a schizophrenic public.

Standardized tests provide tangible results that individuals are not all equal in terms of the characteristics being measured by the tests. Part of the public opinion dichotomy about schooling centers on the issue of whether differences among students should be identified and treated; these attitudes, in turn, are related to what some writers describe as the decline of meritocracy. In the movement to emphasize the equality of rights for all people and to rid society of policies and procedures that discriminate unfairly and on the basis of irrelevant factors, there has been great difficulty in, and different 
opinions about, retaining those processes which are based on appropriate and humanistic recognition of individual differences so that each student can be assisted, frequently in different ways, to mature and develop optimally.

One effect of these attitudes as manifested in the schools is the distribution of grades. The use of credit-no credit systems and grade inflation may reflect a growing reluctance of educators to describe differences even when they exist on factors that are readily definable and measurable. There seems to be resistance to recognizing excellence/merit and deficiencies in classroom achievement; reports to parents and the general public often minimize the variability that exists. Thus, results on standardized tests which do point out differences understandably cause alarm, resentment, and attacks on the messenger that brings the bad news. Standardized tests are inimical for those who believe or feel more comfortable in accepting the equality of all people on all characteristics.

\section{The Accountability Trend}

Another current social trend is affecting the attitude of some people toward standardized tests. In the past decade the concept of accountability has been applied to schools and individual teachers in forms that vary from rational and professional to the other extreme of witch hunts and an opportunity to "do to schools what we haven't been able to do under other pretexts." Almost all professional educators accept the fact that they are responsible for the wise stewardship of public funds and the careful nurturance of the children who have been entrusted to them by parents. But professional educators are incensed, as any group should be, by unfair and irrational approaches that equate school productivity to assembly line input/output models for purposes of accountability.

All too often, scores on standardized tests have been used as weapons by critics of schools and advocates of accountability. The attackers have demonstrated little understanding of test technology and have magnified their errors by assuming that the only achievements worth considering are those measured by standardized tests. These fallacies have been combined with the graceful avoidance of any consideration of community and social factors that may impinge more stringently on school success than any school variables, including teacher effectiveness or curriculum.

There are compelling reasons to sympathize with beleaguered teachers when critics are upset by results that show 50 percent of a local class below a national grade level norm (is the definition of the median the villain?); when the critics had been backing a vested interest in health education, consumer education, career education, humanistic education, and other topics added to school responsibilities and now ignore the impact the addition of these curricula has on the time available for the "traditional" subjects; or when the critics ignore factors such as family mobility, single parent homes, corruption in government, and two-breadwinner families, and the effect these social trends have on student interest in and parental support of schools. Standardized tests do provide a potential weapon for an unreasonably critical local community, particularly when school officials do an ineffective or incomplete job of interpreting the results within the milieu of the community.

\section{The Family Educational Rights \& Privacy Act and Consumer Advocacy}

The preceding point is related to another factor that may contribute to the recent attacks on standardized tests: With the Buckley-Pell amendment guaranteeing the right to know, parents and members of the community have been privy to test information that schools, perhaps unwisely, had never released before. "These data are too technical for the layman" and "you may abuse this information because you don't comprehend the limitations" characterized many schools until the law forced them to release the information to those who had the right to receive it. A complete measurement program requires an effective reporting process, and test data are not too technical when presented in appropriate ways. But the point is that parents now have the right to all information about their children, including standardized test data, and the threat of this open system leads some to conclude that standardized tests are too dangerous to continue to use.

The right-to-know legislation is just one manifestation of the consumer advocacy movement that has had a major impact on everyone, with the testing industry being one of the more recent targets. This movement is just one facet of the current social scene affecting schools that 
impacts on testing and makes good reading in the weekly news magazine.

\section{SOME PREMISES ABOUT EDUCATION AND EDUCATORS}

Within the turbulent society that has its effect on schools and standardized testing, some premises about schools and life need to be established before a "case" can be made for standardized tests. These include:

1. Academic, substantive achievement is an important goal of the school;

2. A common set of goals determines at least a major part of the curriculum of American schools;

3. Instruction and curriculum should be based on the best evidence possible;

4. Excellence should be identified and rewarded, and deficiencies should be identified and remediated; and

5. Sincere and rational educators will use information wisely and in the best interests of their students.

1. Academic achievement, including the basic skills and basic disciplines, is an important goal of the schools. Some would argue that this goal defines the raison de'etre for schools, the unique role that schools are to play among primary and secondary social institutions. For purposes of this treatise, however, we need not agree that academic achievement is the single most important reason for schools to exist, only that academic achievement is one of the legitimate goals of the school.

In the United States education has been deemed essential for effective citizen participation required in a democratic society, and essential in fulfilling the basic tenet of our country that we have a collective responsibility to provide opportunity for all people to develop as fully as they are motivated and capable of achieving. The three R's along with the cultural components from history, geography, government, and literature, and a basic introduction to physical and biological science, formed the central focus of the original public schools and have continued to be a major part of the K-12 curriculum. Though schools have been asked to add other subjects and topics and even though short-term priorities have focused on topics outside the core or basic areas, the three R's and the basic disciplines have continued to represent a major component in the cur- ricula within schools of this country, as well as the mark of an educated person and the minimum requirement for intelligent citizenship and personal freedom to seek the level and type of life desired.

2. A common set of goals determines at least a major part of the curriculum of American schools. Although local districts retain autonomy, to a large extent, in establishing curricula and goals for schools, a great deal of commonality is found among the programs in the thousands of districts of this country. Some of the similarity results from the influence of commercially available instructional materials, but much is attributed to what is known about developmental stages of children and to the similarity of hopes, aspirations, and expectations among people in this country, from farms to urban dwellings, and from the southwest to the northeast corners of the country.

Though we take great pride in local autonomy and protect against moves to centralize control, as well we should, the fact remains that state laws governing age of school entry and leaving are similar and that more similarity than difference exists in the basic curricula. Vocabulary lists include the same words; developmental reading is introduced at the same grade level; grammar, syntax, and punctuation are taught according to the same rules; and math skills are introduced in the same order at about the same grade levels.

Similarities in the content and goals of schools are highly desirable, if not absolutely necessary, in a society with a high degree of population mobility and in a country where citizens tend to identify with national interests more than regional and local interests. The current situation in the United States with regard to these facts suggests that the commonality of basic educational programs will continue, perhaps even expand, in the near future.

3. Instruction and curriculum should be based on the best evidence possible. Professional educators and many people in the general public long have rejected the idea that all children of a given chronological age or grade level should study the same materials at the same time under the same conditions. The extent to which individualized programs actually are implemented varies considerably from school to school and from classroom to classroom, but most teachers and parents do pay homage to the belief that individuals differ and that programs and instruction should be appropriate for the interests, ability, aspirations, and readiness of individual 
children. To accept without modification a commercially available program and/or to teach all members of a class in the same way denies the rights of those for whom the program and instruction are not optimal.

Information that will assist curriculum committees, administrators, and individual teachers in planning and implementing programs and daily instruction can be obtained in a variety of ways. These include observation by perceptive professionals, review of cumulative records, locally devised assessment procedures, and comprehensive testing programs using standardized tests. The principle of parsimony should guide selection of the data gathering instrument and technique. When reliable and valid information for a given purpose can be obtained in a casual, inexpensive, and unsophisticated way, that approach should be used. When the decision requires information that cannot be obtained through such means, however, educators should turn to an approach that will provide the type of data required. In all cases the appraisal system should be the least expensive and least disruptive approach that will produce the information required for the decision to be made.

4. Excellence should be identified and rewarded and deficiencies should be identified and remediated. The latter part of this assertion would be closer than the former to universal acceptance in the present society, but both of the concepts - excellence and deficiency - are relative and must be defined operationally as a requisite for the corollary actions - reward and remediation.

Often, we have said and heard that the most important resource of this country is its people. Advances in all societies and in all fields have occurred largely because of the efforts of talented individuals whose talents have been recognized and fostered. The need remains to identify excellence, exceptional accomplishments in science, creative writing, the social sciences, art, music, and the skilled crafts. Individuals must select for themselves the fields they wish to pursue and cultivate, but educators should help all students develop an understanding of their relative strengths and weaknesses and their talents among people in general. Development of a realistic self concept is an important part of maturation and achieving independence and self sufficiency. The identification of excellence, in an absolute sense, is an important social need so that potential leaders and contributors to a better life can be provided the appropriate educational opportunities.

Exellence and deficiencies are important also in a relative sense. When progress and achievement are never recognized and applauded, subsequent performance tends to become less effective. Many studies have shown that laissez-faire or neutral behavior by an authority figure is less effective than either negative or positive reactions to a person's performance. On this basis many instructional strategies include the recognition and reward of correct behavior as a means of enhancing subsequent behavior. As noted above, excellence can be thought of in a relative way. The worst student in a class, who applies a minor part of a process correctly, has achieved excellence and will profit from recognition of that achievement. (This does not imply that average or poor accomplishment in terms of some absolute standard should be treated as achievement of a final goal.)

Teaching involves, in part, assisting children in assessing and accepting their profile of talents and then helping them to set and accomplish reasonable goals. For less talented students, the goals may represent small increments and, for highly talented students, large increments. The evaluation of progress and its reward, in these cases, should be defined individually, but schools have a responsibility for assisting students to continue to develop toward their potential, whatever that may be, on some absolute standard of accomplishment.

Inherent to the identification of excellence is the recognition of deficiencies. When excellence at some level is a goal, anything less must be a deficiency. Schools should insist continually that students strive to acomplish all relevant goals, and educators should accept as a reasonable challenge the guidance and assistance of students in achieving those goals.

For the large majority of school-age children, a reasonable set of goals includes development of the basic skills and learning the basic principles essential for effective citizenship. For those who are capable, educators should not accept performance below that level; the evaluation system should include attention to such basic performance, and those who fail to demonstrate adequate accomplishment should receive the additional help needed to reach that level.

5. Sincere and rational educators will use information wisely and in the best interests of their students. Teachers, specialists, and administrators have chosen their vocation, in large part, because of their interest in helping children develop into effective and fulfilled adults. They have been trained to collect, interpret, and use information to enhance their work with the children for whom 
they have educational responsibilities. Almost everyone can cite exceptions to these generalizations, but in the main they apply; to assume otherwise would create the need to replace the present educational system with a new, untried approach that would be built on some noxious and eventually destructive premises. A system built on an assumption that the only safe teachers are those who know virtually nothing about their students is the first step toward a lockstep, sterile social institution.

On the other hand, problems associated with educator/student interactions arise more from a lack of appropriate information than from inability to use the information available. If there is a real fear that teachers, counselors, and administrators will accept the information provided by one measure of intelligence or one anecdote (and the evidence does not support this as a general situation), the problem stems from a deficiency, not a surplus, of information.

To deprive teachers of comprehensive information relevant to educational planning and instruction is to deprive students of optimal learning conditions. A goal of an educational system should be to provide teachers with the information necessary for the decisions that must be made on a semester, weekly, and daily basis, and to assure the competence of teachers to interpret and use the information effectively.

Many of the issues associated with educational measurement are not really technical problems but, rather, value judgments related to the philosophy and goals of the community. If a school is supported as a means of providing appropriate opportunities for all citizens to develop optimally in the characteristics associated with the basic skills and disciplines, teachers must have the information needed for individualizing curriculum planning and instruction. On the other hand, if schools are to be custodial institutions with more emphasis on producing homogeneity than on optimal student development, a different approach could be taken with regard to measurement programs. If teachers are viewed as change agents, they need and will use information; if they are custodians, measurement is probably unnecessary.

In recent years standardized tests have been criticized for various shortcomings and, in some cases, because they are part of an educational system and philosophy unacceptable to a disenchanted and/or maligned segment of society. Schools are important, highly visible social institutions; most parents and many other citizens take great interest in what schools do and how well they accomplish their purposes. Dissatisfaction with schools and changes in societal values account in part for recent anti-test statements. Attitudes toward standardized tests depend to a large extent on the premises and the goals of education that are held to be important. Since tests are merely instruments to be used as part of a broader process of delivering educational services, criticism of standardized tests is inevitable when schools more generally are the focus of criticism. Nevertheless, if certain assumptions about school roles and responsibility are acceptable, standardized tests have a unique contribution to make in improving the effectiveness of education.

\section{THE VALUES AND USES OF STANDARDIZED TESTS}

The major values of standardized tests derive from the type of needed information they provide that is not available through other types of assessment procedures. Some decisions that must be made in planning and delivering educational services, and in reporting accomplishments to and obtaining support from the local community, require information uniquely provided by norm-referenced standardized tests. The qualities and characteristics that make this so include:

1. Standardized tests are designed to reflect a national view of the traits measured;

2. Standardized tests provide comparable scores across the various traits measured;

3. Standardized tests provide comparable scores across time (that is, continuity of measurement); and

4. Standardized tests provide data that allow local performance to be compared with that of various reference groups.

Each of these characteristics is important to a number of school decisions and responsibilities, ranging from those made at a district-wide level to those that affect an individual student directly. Within a school system a communication network exists between the school board representing the community, and its central office staff, and personnel in department, building, and classroom positions. The communications relate to the goals and priorities that are translated into educational practices and the accomplishments and needs at each of the levels of the network. 
Results from standardized tests and, more importantly, their interpretation, are part of the information in the network. The extent to which standardized tests are good and potentially useful should be judged in terms of whether they provide unique or corroborative information to improve decisions and reporting within the school communications network.

\section{Design Reflects National View of Traits Measured}

Group tests of ability (intelligence) sample a domain of skills with educational significance. They are based on theories and empirical research that have passed the test of review and debate within a scholarly community and, thus, the tests reflect definitions that are national, sometimes international, in scope. Rather than attributing to these measures some aura of innateness or inevitability, educators should treat them as measures of achieved or developed skills. These tests assess characteristics necessary for development of cognitive knowledge and provide an indication of maturation level of the characteristics.

Standardized achievement tests sample widely accepted objectives and curricula held to be important for continuous educational development and ultimately effective adult personal and vocational lives. The tests are based on reviews of curriculum guides, commonly used instructional materials, and statements prepared by professional organizations. They are subjected to review by professionals in the disciplines and by classroom teachers. Test items must have good psychometric qualiities, and test scores must meet state-of-the-art requirements for validity and reliability.

Establishment of educational priorities and curriculum emphases depends largely on the values and philosophy of the local community, but the process also should be influenced strongly by the nature of the student population, in terms of both talents and prior achievement.

A great deal of information about the talents of local youth can be obtained from information collected by teachers and other school personnel. This type of information is based primarily on personal observations of students during the performance of various educational tasks, and certainly is important in developing a meaningful profile. Observation, however, provides information more directly related to level of performance in complex tasks than to potential; more related to applying a combination of skills and attitudes than to measures of discrete talents.

Locally obtained information about student talents is a good supplement to and a necessary check on the results of standardized tests of ability, but alone they provide an insufficient basis for firm conclusions. Standardized tests provide "cleaner" data in that each subtest focuses on a narrowly defined skill, and intercorrelations with other subtests are known. In addition, results on such tests are not influenced by interpersonal histories, cultural or personal value systems, or any of a number of other factors that influence interpersonal assessment. Although it is desirable, if not essential, that a complete evaluation and action decisions take into account all of the relevant information, measurement of a specific characteristic should be as pure and uncontaminated as possible. Individual, independent measures can be used in various combinations for different purposes, but to be of maximum usefulness, they should contribute unique information.

A national perspective of achievement provided by standardized tests is important in local evaluation and planning even though a perfect correspondence between test content and local curricula seldom exists. Generally, the differences, particularly in the skill areas, are attributable to the fact that local goals cover more topics than the test does. When this is the case, what the test does cover - the most widely accepted goals - is valid as far as it goes, and information from the test is useful in assessing the core topics. In a society that values local autonomy in education, a perfect one-to-one correspondence between test and curriculum would be viewed with alarm.

In the few cases when the tests cover material not included in a school's curricula, local educators might profit from studying the reasons why their program omits nationally common topics or goals. Of course, there is always the possibility that the local program requires an emphasis so different that basic, common topics are omitted, but it seems unlikely that this would be true to the extent that no appropriate standardized achievement test can be found.

\section{Comparable Scores Across Traits Measured}

Many educational decisions, ranging from establishment of district-wide priorities to the allocation of time 
for one day in an individual classroom, require comparisons of student talents and achievements across the major curricular areas. For such comparisons (called profile analysis) to be meaningful, measurements of the various areas must be available in comparable units. Educational measurement lacks absolute scales, but standardized tests are designed to provide comparability across the subtests of a battery; thus, the peaks and valleys of a school or individual student profile are indicative of of areas of relative strength and weakness.

At a school district level, decisions are made regarding allocations of funds and personnel to build on district strengths and to remediate weaknesses. A district that is above the 90th percentile in all curricular areas may wish to improve the weakest of its programs. In a district with low overall achievement, priorities must be established to overcome the deficiencies of most serious concern. Standardized tests provide data that allow for - in fact, enhance - the identification of those areas, and when interpreted within the knowledge of district goals and curricular patterns, provide a sound basis for decisions. Establishing district priorities in the absence of comparable measures of performance is a guessing game that is neither necessary nor acceptable when limited resources must be used efficiently to accomplish community educational goals.

At the department and school building levels in most districts, similar decisions must be made and the requirement for adequate data is just as important. Within an English or Science department, priorities must be established and comparisons across major curricular topics are necessary. At the classroom level, instructional plans are made at the beginning of the year and modified as additional information becomes available. The plans include gross decisions about the level at which instruction should begin, about the texts, reference, and other instructional materials that would be appropriate, and how instructional time should be allocated to build effectively on talent and prior achievement of individual students.

Locally developed measures and criterion- or domainreferenced tests do not provide comparable scales of measurement. Although talented, sensitive teachers might have some clues as to particular areas of strength and weakness, standardized tests may confirm the "hunches" or, as often happens, show that subjective local appraisal is not entirely accurate.

Profile analysis is an important part of decision processes, for high as well as low achieving districts and students, particularly when budgets are not sufficient to cover all needs optimally. Standardized tests are unique in providing data that promote decisions based on identification of relative levels of accomplishment.

\section{Comparable Scores Across Time}

Growth and development may be more important measures of school and individual accomplishment than status measures obtained at some point in time. To assess growth, the measures used must provide continuous scales expressed in comparable units from year to year. Again, because of the lack of absolute scales of measurement, local tests and criterion - referenced tests are insufficient for following progress over time. Grade equivalent, age equivalent, and standard score scales on standardized tests do provide a basis for this important part of an assessment program.

Educational planning and goals usually involve vertical K-12 articulation with the expectation that activities in successive grade levels will guide student development toward accomplishment of goals by the time of high school graduation. Local curriculum sequences frequently differ somewhat in terms of the levels at which certain concepts and skills are introduced and emphasized. Thus, any status measure involving a comparison with national norms must be interpreted in light of local curriculum guides. For example, a district may introduce some topics related to using sources of information a grade or two later than is typical nationally. In such cases, local achievement in that curricular area would be expected to lag behind national performance in the early grades and then show a sudden spurt at the grade level of local emphasis. To know whether such growth occurs, a continuous scale of performance is needed.

Progress over time is a factor of utmost importance in evaluating curriculum and instruction. If deficiencies exist in either the curriculum plan or instructional competence, minimal progress will occur and will be reflected in the testing program results. A one-time occurrence might prompt local attention and review without leading to a definite conclusion that a problem exists; but, if subsequent testing consistently points out the lack of growth at a certain grade level, more serious attention can be given to assessing the reason for the problem. For example, if student progress in mathe- 
matics problem solving, as reflected in annual standardized test results, plateaus in grades 5 and 6, the intermediate math curriculum might need revision or teachers of those grades might need inservice education to improve their teaching skills or content knowledge.

The information base required for effective local educational decisions should include growth as well as status measures. Assessment of progress should be combined with the profile analysis of status results as priorities are established and allocations are made. Again, standardized tests are unique in providing sufficient data for these important decisions.

\section{Comparison of Local Performance With Other Reference Groups}

Some people minimize the importance of national norms as part of a total school assessment program. They often claim that all local conditions differ in some ways from the typical national condition and that assessment of achievement against some standard of excellence is more important than achievement relative to a norm group. These claims are questionable and, even if true, would hardly be sufficient arguments to justify elimination of norm-referenced standardized tests.

Throughout this presentation, emphasis has been given to the need for careful interpretation of data obtained from standardized tests. The differences between the local school and national averages must be taken into consideration in all serious evaluation programs. Student talent, parental values, levels of financial support, and local curricular patterns have major impacts on the achievements in a given school district, and one reason for giving standardized tests is to obtain thorough, objective, and reliable data regarding talents and accomplishments so that evaluations can be based on solid information rather than on guess work.

Locally prepared instruments and criterion-referenced tests lack an external referent or standard and, thus, performance on these tests can be interpreted only in terms of subjective judgments about performance levels. Such judgments obviously provide a tenuous basis for local districts to assess how well students are achieving relative to their capabilities and relative to accomplishments under comparable conditions in other communities.

A given level of performance on a test is a fact and can have vastly different meanings in different school sys- tems. A school average score at the 40 th percentile on national norms would be regarded as intolerable in a district that has goals virtually identical to those covered on the test, is well above average in per-pupil expenditures, and employs only the most highly qualified teachers. The same level of performance might be lauded in a district with 80 percent of its student enrollment from low income homes, and which spends 75 percent of the national average in supporting education and has a 40 percent annual turnover in its professional staff.

But two additional points concerning the above comparison must be considered. First, graduates from both of these districts are entering the same society. To develop a realistic self concept and reasonable hopes and expectations, students need to know how their accomplishments compare to those of students from other communities (or schools). In a highly mobile society, local norms, or no comparisons at all, fail to provide a sufficient information base for personal assessment and planning. Thus, national norms are helpful for school district evaluation purposes and for helping students to have a better perception of themselves and the nature of the competition they will face in seeking admission for further schooling and for obtaining employment.

Second, because national norms do have limitations in terms of some evaluation needs, many publishers of standardized tests provide special norms useful for particular situations and needs. Achievement norms for students of certain narrowly defined ability levels provide the basis for assessing local performance against that of students with similar ability. Regional norms, norms for large cities, and other variations have been developed to assist communities in selecting appropriate external reference groups for specific types of comparisons. Generally, these special norms are obtained along with the national norms so that different evaluation needs can be served.

Again, education is an important community responsibility, and parents and other citizens take a great deal of interest in the accomplishments of schools they support. With the ever increasing costs for education, community interest in schools likely will grow, accompanied by added demands for substantive reports of school accomplishments. Certainly, a community has the right to know about successes and problems in its schools, and administrators, logically, would want to share such information in a professional way. Pride should be taken when deserved, and accomplishments, when reported objec- 
tively, should be an encouragement to citizens for continued support of the schools. Deficiencies, in a relative sense, may be remediable with an increase in support, and how better to convince a community of needs than to report the results of standardized tests properly interpreted.

Education is a unique enterprise, since goals and levels of support are determined by lay citizens while the professionals are expected to implement programs to accomplish the goals and use resources efficiently. Education is truly a shared endeavor, and an appropriate evaluation system can help in strengthening the community/educator partnership needed for continued and improved success.

\section{CONCLUSION}

The preceding discussion has emphasized the value of standardized tests for decision making processes within school systems, giving four characteristics of standardized tests that make them unique within the data gathering processes available to schools. Other virtues of standardized tests could be added: efficiency and cost effectiveness as tools for collecting vital information thus freeing teachers to devote more time to instructional planning and work with individual students; the ability to identify talents and accomplishments that otherwise may go undetected because of a student's poor attitude, motivation, interpersonal skills - or perhaps because of cultural biases that cloud educator sensitivity and objectivity.

Standardized tests are not perfect tools; their value is influenced largely by the skill with which people interpret and use the results. These tests only sample the domain they claim to measure. They are neither complete nor infallible instruments. They do not tap innate student characteristics; they measure the demonstration of acquired talents. They do not measure all the important topics of interest to schools and individuals - thermometers do not measure humidity.

A valuable tool can be misused. Lasar beams are used both to perform delicate operations on the retina of an eye and as weapons of destruction. Educators must select standardized tests appropriate for identified purposes. This responsibility should not be abdicated. Educators must analyze, interpret, and decide how to use results from standardized tests; failure to do so in the past has been a contributing factor to the misuse and concomitant criticism of school practices.

Professionals and the general public probably know more about standardized tests and their limitations than they do about any other source of information concerning student characteristics. Authors and publishers have developed elaborate, detailed reports about the reliability of tests, relationships between scores and other variables, method and rationale used in developing the tests, and limitations of the data. Similar information concerning teacher speculations, anecdotal records, locally developed instruments, and other data gathering techniques would improve the entire decision making process. The availability of these technical data would provide a more adequate basis for comparing the usefulness of standardized tests with other possible data sources.

Educators must continue to seek improvements in the effectiveness and appropriateness of instructional programs. Used by qualified people, standardized tests can make a unique and important contribution. To eliminate the use of standardized tests would be a major step backward, contributing to an educational system in which all individuals would be provided locally determined instruction whether appropriate or not. The technology of scientific appraisal would be replaced by the former technology of the dunce cap and birch rod.

FOCUS ON EXCEPTIONAL CHILDREN is published monthly except June, July, and August as a service to teachers, special educators, curriculum specialists, administrators, and those concerned with the special education of exceptional children. This journal is abstracted and indexed in Exceptional Child Education Abstracts, and is also available in microfilm from Xerox University Microfilms, Ann Arbor, Michigan. Subscription rates, $\$ 10.00$ per year. Copyright 1978, Love Publishing Company. All rights reserved. Reproduction in whole or part without written permission is prohibited. Printed in the United States of America. Second class postage is paid at Denver, Colorado.

$$
\begin{gathered}
\text { Executive and Editorial Office } \\
6635 \text { East Villanova Place } \\
\text { Denver, Colorado } 80222 \\
\text { Telephone (303) 757-2579 }
\end{gathered}
$$

\section{EDITORIAL BOARD}

Edward L. Meyen University of Kansas
Glenn A. Vergason Georgia State University

Richard J. Whelan

University of Kansas Medical Center 


\section{CLASSROOM FORUM}

\author{
Beverly Dexter \\ Assistant Professor \\ Lynchburg College, Virginia
}

\section{I realize that PL 94-142 requires that my child be tested before being placed in the special educa- tion program, but I question the value of all this testing. Can't the teachers determine what my child needs without these tests? What all is involved in this testing anyway?}

Testing, as a part of evaluation, is done for several reasons. The main reason should be to find out how a child learns best. In most instances, however, testing is done to find out where a child is academically, mentally, socially, and/or motorically. When a child is tested academically, specific subject areas are investigated, usually through use of standardized achievement tests. Sample problems or examples, which have been selected through the standardization process, are given on the test. For example, if a high percentage of eight-year-olds in the standardization population are able to answer a specific question correctly, that question is regarded to be a suitable example for all eight-year-olds who take the test. The same is true for the mental, social, and motor tests, which may be termed as developmental types of tests.
Several considerations need to be taken into account in using standardized norms for comparing achievement levels of children. Until recently, the majority of these tests were developed using only majority ethnic children in their populations. We now recognize the fallacies of this practice, along with the regional differences that need to be taken into consideration when youngsters are to be compared on specific test information. For example, to most children a ramp is something you walk on to get across an open area, such as from the shore to a small boat. Children who live in the mountains of western North Carolina, however, would say that a ramp is something to eat. Why? Because they have grown up celebrating "ramp festivals" that extoll the virtues of a potent wild onion which grows along the mountainsides. They might even tell the examiner that by eating ramps they are guaranteed a holiday from school because of the rank odor permeating the atmosphere around the brave souls who partake of this plant.

Other considerations to be taken into account in testing a child include family background (Has the family moved frequently? Does the child live with natural parents or with relatives? How many children are in the family? etc.); medical history (Was he/she a healthy baby? Have any allergies? Taking medication regularly? In good health? etc.); current disposition (Is he/she upset over a traumatic experience of some kind? Does he/she have friends? etc.); academic record (Were any grades repeated? Any subjects failed? Are letter grades appropriate for accomplishments? Is the child currently working at grade level in all academic subjects? etc.).

All these considerations must be factored into the results of any test, but especially standardized tests, which usually allow for little if any flexibility. If the purpose of the testing is to place a child academically, the person doing the testing should become familiar with all the above factors, including the answers to and implications of the questions posed.

Currently, much debate within the fields of education and psychology is focused on the use of standardized IQ scores. California has dropped IQ testing entirely from its evaluation procedures; other states are threatening to follow suit in the near future. By eliminating the IQ score, these professionals believe they will be less biased than in the past in their overall evaluations of children. The National Association of Elementary School Principals called for a "moratorium on IQ testing" in June, 1975, because of what they called the misuses of the tests and 
their results. The organization has spoken against such testing since 1972, but 1975 was the first time a policy statement had been issued concerning the matter. Several other professional groups, including the National Education Association, recently have made similar statements.

This does not necessarily mean that all such evaluation procedures should be abandoned. It does mean that educators and psychologists currently are questioning the way in which test results have been interpreted in the past. When one considers that a child's entire life style may be affected by the interpretation of tests by one individual, the reality becomes rather startling.

If, however, interpretation of test results is combined with teacher observations, parent observations, and interdisciplinary communication, these results may be used to help develop an educational program which will benefit the child. By combining knowledge and experience, professionals can draw upon their individual expertise to help the child obtain realistic educational goals. These goals should be determined by eliciting input from the child, along with the professionals and parents. In addition to the IEP, contracts often are used to make goals "official" and realistic to all parties involved. Specific strategies are outlined for obtaining specific goals, and the "roles" of the child and teacher are stated clearly. 